\title{
A randomized controlled trial to evaluate utilization of physical activity recommendations among patients of cardiovascular healthcare centres in Eastern Slovakia: study design and rationale of the AWATAR study
}

Aurel Zelko ${ }^{1,2^{*}}$ D, Alena Bukova ${ }^{1}$, Peter Kolarcik ${ }^{3,4}$, Peter Bakalar ${ }^{1}$, Ivan Majercak ${ }^{5}$, Jana Potocnikova ${ }^{1}$, Sijmen A. Reijneveld ${ }^{2,6}$ and Jitse P. van Dijk $k^{2,4,6}$

\begin{abstract}
Background: Guidelines on modifiable risk factors regarding cardiological patients are poorly implemented in clinical practice perhaps due to low health literacy. Several digital tools for improving lifestyle and behavioural intervention were developed. Our primary aim is to evaluate the effectiveness of a digital exercise prescription tool on the adherence to physical activity recommendations among patients with cardiovascular diseases.

Methods: A randomized controlled trial will be realized in cooperation with Cardiovascular Health Centres in Eastern Slovakia. Patients recruited through their cardiologists, will be randomised at 1:1 ratio to the three-months' experimental condition or control condition. The experimental group will receive standard lifestyle consultation leading to individually optimized prescription of physical activity. The control group will receive standard, usualcardio-care lifestyle counselling, also in the domain of physical activity. The digital system will be used for optimized exercise prescription. The primary outcome is a change in the patient's adherence to exercise recommendations. Data will be collected in both groups prior to consultation and after 3 months.

Discussion: This study protocol presents background and design of a randomized control trial to investigate the effectiveness of a digital system-provide exercise prescription tool on the adherence to physical activity recommendations. An optimized exercise prescription that better reflects patient's diagnosis, comorbidities and medication can have a significant impact on secondary prevention of cardiovascular disease. This trial can provide important evidence about the effectiveness of digital exercise guidance in everyday practice of cardiovascular healthcare.
\end{abstract}

Trial registration: The study was registered on 1st November, 2017 and is available online at ClinicalTrials.gov (ID:NCT03329053).

Keywords: Exercise prescription, Digital exercise prescription tool, Cardiovascular disease

\footnotetext{
* Correspondence: aurel.zelko@upjs.sk

${ }^{1}$ Institute of Physical Education and Sport, P. J. Safarik University, Ondavska

21, 04011 Kosice, Slovakia

${ }^{2}$ Graduate School Kosice Institute for Society and Health, Faculty of Medicine,

P. J. Safarik University, Trieda SNP 1, 04011 Kosice, Slovakia

Full list of author information is available at the end of the article
} 


\section{Background}

The age-standardised prevalence rate of cardiovascular disease (CVD) among the Slovakian male population $(9,403$ per 100,000$)$ is the highest within the EU countries, while among females the comparable prevalence rate, approaching 7000 per 100,000 , is the second highest across the EU member states [1]. In response to these statistics, a number of action calls are nowadays proclaimed for better and more effective prevention of CVD [2-6]. Exercise prescription is an essential part of primary and secondary CVD prevention programs.

Increasing exercise is clinically efficient in blood pressure management. A systematic review and metaanalysis of randomized controlled trials focused on the effects of exercise intervention in normotensive and hypertensive patients confirmed that resistance [7] and endurance [8] training lowers the systolic and diastolic blood pressure in patients with CVD. Exercise-induced hypertension reducing effects were confirmed in young [9], middle-aged [10] and elderly [11-13] population and also in patients with low responsiveness to hypertension medical treatment $[14,15]$. Physical activity (PA) is seen as an effective modulator of the endothelial function [16], which was recognized as a main trigger of the cardioprotective effects of exercise [17-20]. Regular exercise performed by middle-aged and older healthy men should prevent age-associated loss in endotheliumdependent vasodilation and restore endothelial activity to levels similar to those of younger men [21]. Moreover, PA was able to attenuate the deleterious effect of nitric oxide synthase gene polymorphism on the systolic blood pressure [22] and has shown to have positive impacts on glycaemic control [23], cholesterol profile [24] and lipoprotein subclass profile [25].

To ensure maximal effectiveness and safety of exercise interventions [26, 27], experts in the field of cardiovascular health are regularly updating the guidelines containing recommendations for PA of patients with CVD. Between 2004 and 2006, the European Society of Cardiology (ESC) published miniseries of position papers that summarized specific recommendations for PA of patients by pathology [28-33]. A three-part miniseries published by the ESC in 2012 was describing the importance of PA and exercise modalities in the management of cardiovascular health. This time, exercise recommendations were dedicated for the general population [34], individuals with cardiovascular risk factors [35], and individuals with CVD [36]. The latest upgrade of ESC's guidelines for PA was done in the year 2016 [37].

Despite the strong emphasis on regular exercise during lifestyle counselling [38], in the EUROASPIRE IV (European Society of Cardiology survey on the lifestyle, risk factor and therapeutic management of coronary patients), more than $59 \%$ of the interviewed patients reported little or no PA [39]. To clarify these conflicting observations, we need take to account the ecological factors [40], the quality of communication between care-providers and patients, $[41,42]$ and the patient's skills to access, understand and use of diseasespecific instructions and recommendations [43, 44]. The latter domain is also labelled as the patient's health literacy (HL). The HL level influences the patient's use of healthcare, quality of disease management and health risk behaviours [45] and reflects patient's proactivity in attempting to utilize health literacy skills [43]. Sufficient HL is significantly associated with improved health outcomes with a lower cost of care [45], while HL inadequacies can compromise patient safety, worsen management of a disease and increase the incidence of health conditions requiring intense medical assistance or hospitalization [46]. In older adults, inadequate HL was significantly associated with poor implementation of PA recommendations [47]. For improvement of patient's accessibility and applicability of health-related knowledge in real life, we need to emerge that patients and health professionals cannot address these needs independently [48].

For cardio-clinicians nowadays, the available time is very limited to implement all parts of the long versions of disease-, comorbidity-, and medication-specific guidelines for prevention of CVD [28-37]. Behavioural interventions mediated by a digital tool may be a feasible route to improve cardiovascular-related medication adherence and clinical outcomes [49-51]. For the improvement of exercise prescriptions accessibility and applicability in the secondary prevention of CVD, a digital support system for optimized exercise prescription seems to be appropriate. In response to this request, the European Association of Preventive Cardiology developed and introduced the Exercise Prescription in Everyday Practice and Rehabilitative Training (EXPERT) tool [52]. In this "utilization of physical activity recommendations among patients of cardiovascular healthcare centres" (AWATAR) trial, we will assess whether the EXPERT tool can effectively increase the utilization of exercise recommendations among patients with CVD. The effects of such a digital intervention may further be moderated by HL. Therefore, we will try to confirm that patients with higher HL might benefit more from the digital tool prescription compared with patients with lower HL.

\section{The aims of the AWATAR trial are therefore}

(1) to determine and compare the utilization of exercise recommendations after exercise prescription according to digital training and decision support system as compared to exercise prescription following the standard informative procedure among patients with CVD. 
(2) to determine whether HL moderates the effect of exercise prescription according to the digital training and decision support system on the indices of exercise recommendations adherence among patients with CVD.

\section{Methods/design}

\section{Trial design}

To ensure complete reporting and sufficient replicability of our trial, we describe its design following the SPIRIT 2013 Statement [53] and create a schedule of enrolment, interventions, and assessments planned on the trial based on the SPIRIT template (Table 1). The AWATAR study will be the first randomized controlled trial (RCT) in which the utilization of exercise recommendations between the standard lifestyle informative procedure and the digital training and decision system informative procedure will be compared. Based on the reviewed literature, we hypothesize that a higher rate of adherence between the patient's 3 months exercise report and patient's digital tool exercise prescription will be observed in the experimental group compared with a three-months waiting group that receives care-asusual. The trial protocol was approved by Human Research Ethics Committee of the Pavol Jozef Safarik University (approval no. PJSU-V-0825/17-1).

Table 1 SPIRIT schedule of enrolment, interventions and assessments for experimental and control group in the AWATAR trial

\begin{tabular}{|c|c|c|c|}
\hline \multirow[b]{2}{*}{ Timepoint } & \multicolumn{3}{|l|}{ Study period } \\
\hline & Enrolment $\mathrm{T}_{0}$ & $\begin{array}{l}\text { Between } \\
T_{0} \text { and } T_{1}\end{array}$ & $\begin{array}{l}\text { At three } \\
\text { months } T_{1}\end{array}$ \\
\hline \multicolumn{4}{|l|}{ Enrolment: } \\
\hline Eligibility screen & $x$ & & \\
\hline Informed consent & $x$ & & \\
\hline Allocation & $x$ & & \\
\hline $\begin{array}{l}\text { Intervention (either intervention } \\
\text { under study or CAU) }\end{array}$ & & \# & \\
\hline \multicolumn{4}{|l|}{ Assessments: } \\
\hline $\begin{array}{l}\text { Questionnaire on Adherence } \\
\text { to recommendations }\end{array}$ & $x$ & & $x$ \\
\hline PA questionnaire & $x$ & & $x$ \\
\hline Anthropometry & $x$ & & $x$ \\
\hline Clinical data & $x$ & & $x$ \\
\hline Health literacy & $x$ & & $x$ \\
\hline Lifestyle variables & $x$ & & $x$ \\
\hline Socio-demographic data & $x$ & & $x$ \\
\hline Feasibility & $x$ & & $x$ \\
\hline
\end{tabular}

(X - application of procedure in both experimental and control group; \# application of EXPERT tool in experimental group or application of standard informative procedure in control group)

\section{Participants}

All potentially eligible participants from the cooperating Cardiovascular Health Centres (CHCs) will be screened and selected according the inclusion criteria exclusively through their cardiologists and receive written information about the trial. Within a week they will be contacted by phone to be provided by additional details about the trial and to confirm their availability to participate in the study. After telephonic agreement to participate in the study, they will be invited to an introductory session with the treating cardiologist. The cardiologist will review the inclusion criteria as indicated above and the exclusion criteria and discuss with the patient further study details. At a final formal step, a written informed consent form will be obtained from the participants. Following the introductory session, the baseline assessments of participants will be made.

\section{Sample size}

The trial has been designed to detect an effect size of 0 . 33 for the intervention under study compared to careas-casual, regarding the primary outcome of agreement between patient's reported and prescribed exercise indices (type, duration, intensity and frequency - variables summarized in Table 4), with a power of $80 \%$ at an $\alpha$ level of 0.05 (two-tailed). An effect size of 0.60 has previously been shown to be realistic [50] and has sufficient clinical relevance. This requires 150 participants in each group, i.e. a total effective sample size of $2 * 144=288$ participants. Based on the experience with similar projects completed at the $\mathrm{CHCs}$, the expected attrition rate is $25 \%$. This implies that almost 400 participants should be recruited.

\section{Inclusion criteria}

The study aims at assessing the effects in routine care, i.e. for a wide age range and a number of cardiovascular diagnoses on inclusion criteria. To be eligible to participate in the AWATAR trial, patients have to meet following criteria:

- age between 40 and 75 years-old;

- ability to provide informed consent based on information about perceived health benefits and risks connected with participation in the study from the treating cardiologist;

- willingness to accept randomization and participation in the assessment procedures;

- presence of one or more below listed cardiovascular diagnosis (Table 2) at the recruitment moment of participants. 
Table 2 Inclusion criteria: present cardiovascular diagnosis at the recruitment moment of participants

Cardiovascular diagnosis
coronary artery disease (both, with or without percutaneous
coronary intervention)
coronary artery bypass graft surgery, or endoscopic traumatic
coronary artery bypass graft surgery
compensated heart failure (with preserved or lowered left
ventricular ejection fraction)
cardiomyopathy
intermittent claudication
implantable cardioverter defibrillator or pacemaker
ventricular assist devices
heart transplantation
valve disease or surgery
congenital heart disease
non-severe pulmonary hypertension

\section{Exclusion criteria}

After the participants' inclusion, specific exclusion criteria regard minimization the risk of (sudden) exercise-induced cardiac events. Exclusion criteria include the presence of specific CVD problems that significantly increasing risks of sudden cardiovascular events, also identified as potential contraindications of PA on cardiovascular patients. These are summarized in Table 3-List A regarding specific cardiovascular conditions and List $\mathrm{B}$ regarding non-CVD specific exclusion.

Table 3 Exclusion criteria: presence of specific cardiovascular conditions and non-specific exclusion criteria

\begin{tabular}{ll}
\hline List A & Presence of specific cardiovascular conditions \\
& uncontrollable hypertension \\
& decompensated heart failure \\
& severe and symptomatic aortic stenosis \\
& uncontrolled arrhythmia \\
& severe pulmonary hypertension \\
& acute coronary syndromes \\
& acute myocarditis, endocarditis, or pericarditis \\
& aortic dissection \\
& Marfan syndrome \\
& Presence of non-CVD specific exclusion criteria \\
& malignancy (active cancer) or life-threatening disease \\
& bed-bound patient status \\
& participation or plan to participate in other study during \\
trial execution & plan to move during the trial execution
\end{tabular}

\section{Randomization and allocation}

The AWATAR trial will be realized as a two arm, parallelgroup, randomized controlled trial with an allocation ratio of 1:1. Participants will be randomly assigned, with equal probability to fall into each of two trial arms into: the experimental group (EG) and the 3 months waiting list control group (CG). For the allocation process, a computer-generated allocation sequence will be prepared by an investigator with no involvement in the trial. Allocation sequence will be stratified by the cardiovascular diagnosis of participants and will not be disclosed to the cardiologists or persons from the investigation team participating in the trial. This important blinding step will prevent assignment of patients into EG or CG groups according to someone's personal preferences.

For the assignment process, we will prepare identical, sealed, opaque, stapled envelopes, sequentially numbered by generated allocation sequence. Each envelope will contain the written code (EG or CG) indicating experimental or control group. This code containing envelope will be drawn by one member of investigatory team (AZ). The nature of the intervention makes it impossible to ensure blinding of the investigatory team or participants in presented trial settings.

\section{Intervention \\ Experimental condition}

After baseline assessments, patients in experimental group (EG) will undergo behavioural counselling. During the 30min long consultation EG patients will receive standard, usual-cardio-care lifestyle, hypertension and cardiovascular instructions, except recommendations for physical activities (PA). Instruction $\mathrm{s}$ on this PA domain will be provided exclusively through the digital training and decision support (EXPERT) tool. They will receive this information immediately after the baseline assessments by a trained member of the investigatory team (AZ).

The EXPERT tool is an interactive digital training and decision support system for optimized exercise prescription in cardiovascular disease patients. The tool was developed by a working group connecting 33 experts in the rehabilitation of chronic internal diseases and three computer science experts from 11 European countries. During the construction of the system, clinical and rehabilitation experts reviewed all relevant and accessible recommendations, current clinical guidelines, studies and expert opinions in exercise intervention of cardiovascular patients. Specific exercise intervention goals were formulated for each different CVD, CVD risk factor and other chronic non-cardiovascular comorbidity.

The EXPERT tool was designed to provide optimized exercise prescription based on detailed overview of patient's diagnosis, prognostics, complications and medication. The digital system requires data input in four 
steps, the data about patient's clinical and cardiological characteristics (parameters), patient's medication data and data summarizing patient's adverse events registered during exercise testing. The EXPERT tool is able to generate exercise prescriptions even some of the relevant parameters are missing. In this case, unavailable data are not reflected in the prescription process and should negatively affect individualization and optimization rate of recommendations for patient in final.

After execution of the required data input, the EXPERT tool is ready to generate an exercise prescription (type of exercise) defining five regulatory parameters: 1) intensity and 2) frequency of the exercise, 3) duration of each exercise session, 4) duration of the training program, 5) feasibility of the strength training during the training program. Additionally, the prescription contains exercise contraindications and safety precautions for a certain type of exercise. The generated exercise prescription will be explained and discussed in details by a member of the investigatory team and will be printed in two paper copies for the patient. We will forward the EXPERT tool's output in electronic form to patient's email address. All outputs will be safely stored for replication or exercise prescription history review.

\section{Control condition}

Patients randomized to the (3 months waiting) CG will after baseline assessment receive standard, usual-cardiocare lifestyle, hypertension and usual cardiovascular instructions, so also in the domain of recommendations for physical activities. The exercise prescription process during consultation in the CG will be constructed in accordance with published ECS guidelines and recommendations for CVD secondary prevention [54]. The timing and mediator of behavioural counselling of the CG will be same as on the EG. Participants in CG will be informed, that after expiration of 3 months control period, and they will be offered to receive an identical digital-based (EXPERT) exercise prescription as patients in EG. Through the intervention all participants are instructed to maintain the standard treatment. Patients who declined to participate in the trial and those who will cancel participation during implementation of the trial will be asked to complete a short questionnaire to collect basic socio-demographic and behavioural data and explore the reasons for non-participation or noncontinuation in the trial.

\section{Procedure}

Assessments will be conducted at two time points (prior to patient's behavioural consultation and 3 months follow-up the consultation). Completion of measurements should take maximally $30 \mathrm{~min}$. One member of the investigatory team (AZ) will perform all measures in the trial. A dedicated member will undergo a training session to ensure consistency of assessment protocol and validity and reliability of applied diagnostics instruments.

\section{Primary outcome measures}

The primary outcome is exercise recommendations adherence as assessed by agreement between the patients reported and the prescribed indices of exercise. The indices are type, duration, intensity and frequency of exercise. Patient-reported type, duration, intensity and frequency of exercise will be assessed using a short self-report questionnaire (Table 4), reflecting the construction and definition of exercise prescriptions generated by the EXPERT tool. The questionnaire will be filled with assistance of an investigatory team member and he will ask participants to report regularity on exercise over the last year and describe in detail the type, duration, intensity and frequency of exercise realized over the last 3 months. Exercise recommendations adherence will be determined as agreement between indices of exercise prescription delivered by EXPERT tool and self-reported indices of exercise performed in monitoring period (3 months). In the follow up assessment, the last section of the questionnaire will be dedicated on the general evaluation of PA behavioural change (by the question: "Have you registered a change in your PA behaviour during the last three months?"; with options for answer: "Definitely/Partially/Only limited change/Not at all”).

Table 4 Measurement dimensions of exercise recommendations adherence and outcome variables

\begin{tabular}{|c|c|}
\hline Measurement dimensions & $\begin{array}{l}\text { Outcomes variables (independent data } \\
\text { for last } 3 \text { months recall period) }\end{array}$ \\
\hline Type of exercise & $\begin{array}{l}\text { - Endurance training (walking, bicycling, } \\
\text { swimming) } \\
\text { - Strength training (free weight or } \\
\text { resistance strength training, weightlifting) } \\
\text { - Speed training (all short duration exercises } \\
\text { with high intensity) } \\
\text { - Anaerobic training (all exercises generating } \\
\text { "lactate feelings") } \\
\text { - Sport games or mixed/other training }\end{array}$ \\
\hline $\begin{array}{l}\text { Duration of exercise } \\
\text { (in one session) }\end{array}$ & $\begin{array}{l}\cdot 0-10 \mathrm{~min} . \\
\cdot 10-20 \mathrm{~min} . \\
\cdot 20-30 \mathrm{~min} . \\
\cdot 30-45 \mathrm{~min} . \\
\cdot 45-60 \mathrm{~min} . \\
\cdot 60-90 \mathrm{~min} . \\
\cdot \text { - } 90-120 \mathrm{~min} . \\
\cdot 121 \text { and more min. }\end{array}$ \\
\hline $\begin{array}{l}\text { Intensity of exercise } \\
\text { (typical intensity) }\end{array}$ & $\begin{array}{l}\text { - Light Activity: an activity that does not } \\
\text { cause you to 'huff and puff'. } \\
\text { - Moderate Activity: an activity that makes } \\
\text { you breathe harder than normal, but } \\
\text { only a little. } \\
\text { - Vigorous Activity: an activity that makes } \\
\text { you 'huff and puff'. }\end{array}$ \\
\hline $\begin{array}{l}\text { Frequency of exercise } \\
\text { (per week) }\end{array}$ & $\begin{array}{l}\text { - Daily } \\
\text { · 3-6 per week } \\
\text { • 1-2 per week }\end{array}$ \\
\hline
\end{tabular}




\section{Secondary outcome measures}

Secondary outcomes include anthropometry (body mass index, weight to height ratio), performance of leisure time physical activities, parameters of medical comorbidities (classification/severity) and clinical characteristics of the participants (systolic and diastolic pressure; blood total and low-density lipoprotein cholesterol concentration; fasting glycaemia; resting and peak heart rate during exercise testing; and peak oxygen uptake capacity).

Anthropometry Body mass index will be calculated (weight/(height $)^{2}$ ) based on body height $(\mathrm{m})$ and weight $(\mathrm{kg})$ determined by a stadiometer and calibrated electronic scale, respectively. Waist-to-height ratio will be calculated by a standard formula (waist circumference/height), based on body height and waist circumference $(\mathrm{cm})$ measured using a non-elastic tape measure at the narrowest point between the last rib and the iliac crest at the end of a normal expiration.

Leisure time physical activities To measure the prevalence of PA unqualified as sport-related or performanceoriented exercises (gardening, yard work, housework, carrying for another, home repairs) we will measure leisure time behaviours of participants via International Physical Activity Questionnaire - Short Form (IPAQ$\mathrm{SF}$ ). The IPAQ-SF is a validated and reliable questionnaire for assessment of frequency (days per week) and time (minutes per day) of PA realized during a past 7 days recall period in five domains: work, transportation, garden or yard, home, and leisure time [55]. The original English IPAQ-SF version was translated and cross-culturally adapted in several steps according to methodology established and described by the IPAQ developers group [http://www.ipaq.ki.se]. The Slovak IPAQ-SF version was subsequently reviewed by an expert and pre-tested $[56,57]$.

\section{Background measures}

Clinical data included a list of patient's CVD, CVD risk factors, other chronic non-cardiovascular co-morbidities, patient's medication, systolic and diastolic blood pressure, blood total and low-density lipoprotein cholesterol concentration, fasting glycaemia, resting, and known patient's adverse events registered during exercise testing. These data will be collected and reported by patient's cardiologist and transferred from the patient's medical record to the study file.

The Health literacy (HL) level will be assessed using The Health Literacy Questionnaire (HLQ) $[58,59]$. This questionnaire comprises nine domains to provide a detailed profile of $\mathrm{HL}$ of populations, groups or patients of interest. The HLQ is divided into two parts which differ in response categories. Part 1 (domains $1-5$ ) has 4 response categories rating the extent of agreement from 1 to 4. Part 2 (domains 6-9) has 5 response categories rating the level of difficulty from cannot do or always difficult (1), to always easy (5). Each domain was scored as the average of the item scores. The score ranges from 1 to 4 or 1 to 5 respectively, a higher score indicating higher level of health literacy. Cronbachs alpha in an earlier Slovak sample ranged from 0.73 to 0.84 among 9 HLQ domains [59].

Also, lifestyle variables and socio-demographic data will be collected via questionnaire developed for this study. The participants will provide standard information about age, education completed, marital status, number and age of descendants, living and work conditions and history, drinking and smoking habits.

\section{Feasibility}

Eligibility, compliance, attrition and safety rates will be registered during the recruitment and implementation of the study. The principal investigator, in cooperation with the cardiologists will register eligible patients out of all patients from the registries. Also, the number of those willing to participate out of all eligible patients will be recorded. During the intervention period, compliance and adherence data as well as the reasons for discontinuations will be collected. There are no contraindications, but specific measures incorporating partial body weight support may be necessary.

\section{Data analysis}

All data analyses will be carried out using statistical software package IBM SPSS 22.0 or equivalent. Analyses will include standard descriptive statistics, Pearson chisquared test for categorical variables, independent- and paired-sample tests of differences for continual variables (e.g. t-test/U-test, ANOVA) adjusted for baseline values. The agreement between indices of exercise prescription delivered by EXPERT tool and self-reported indices of exercise performed in monitoring periods will be tested using intra-class correlation test. Modelling of associations with possible adjustments will be conducted with regression analysis (linear and/or binary logistic). Analysis will be performed primarily based on intention-totreat. In addition, a per-protocol analysis including only patients with no missing observations of the variable of interest will be performed. All tests will be two-tailed with statistical significance set at an $\alpha$ level of 0,05 .

\section{Monitoring}

The study will be supervised by a Data Safety and Monitoring Board consisting of one independent, internationally recognized clinical researcher (Assoc. Prof. Viola Vargova $\mathrm{MD})$, one representative (cardiologist) from each cooperating Cardiovascular Healthcare Centre as an advisor and experts in health psychology (PK), exercise psychology (JP), trial management (PB), and exercise physiology (AZ). 
The Board will be the policy and decision-making authority of the trial. A principal investigator $(\mathrm{AB})$ will be responsible for the organization of the research activities and communication with study patients, research cooperators and partners. Three investigator assistants will manage the central randomization (PB), project and ethics reporting (JP) and collection, protection, storing and processing of trial data (AZ). All assessments and exercise prescriptions in trial will be performed by one member of investigatory team (AZ).

\section{Discussion}

In the present AWATAR trial the effectiveness of digital training and decision support system on patients with CVD will be investigated for the first time. Meeting PA recommendations is a challenging public health issue. Fulfilment of exercise recommendations is a key factor in CVD prevention [60, 61]. However, adherence rates among cardiovascular patients are deep below the expectation rates [39].

The strength of this trial is its study design, ideal for determining the effectiveness of an intervention in a real-world setting. In the Methods section, we specified a wide range of inclusion criteria to recruit the study population as similar as possible to the population on which the intervention tool is meant to be used. We tried to reflect the normal range of diversity in CVD severity, presence of comorbidities, and medication profiles seen in everyday clinical practice. The intervention (EXPERT) tool is an easy-accessible digital instrument and the outcomes are comprehensible for a range of users, including clinicians, patients, policy makers, and health commissioners. Also, the strong side of this survey is the use of the questionnaire items designed to specifically address the characteristics of exercise prescription for patients with CVD. The questionnaire items were developed by copping the exercise prescription variables defined by EXPERT tool.

The application of waiting control group design is weak side of the presented design. Based on similar studies, we expect that only one-third of patients randomized on control group will agree with control group settings and protocol. The high attrition rate in control group and the subsequently unbalanced drop-out rate between groups should affect internal validity of our study.

\footnotetext{
Abbreviations

ANOVA: Analysis of variance; CG: Control group; CHCs: Cardiovascular Health Centres; CVD: Cardiovascular disease; EG: Experimental group; ESC: European society of cardiology; EU: European Union; EXPERT: Exercise prescription in everyday practice and rehabilitative training tool; $\mathrm{HL}$ : Health literacy; HLQ: Health literacy questionnaire; IPAQ-SF: International physical activity questionnaire - short form; PA: Physical activity; RTC: Randomized controlled trial; SPIRIT: Standard Protocol Items: Recommendations for Interventional Trials
}

\section{Acknowledgements}

We appreciate the co-operation of the CHCs and patient organizations involved in the development of the study. We would like to thank prof. Andrea Madarasova Geckova, the Chair of the Department of Health Psychology, Faculty of Medicine, P. J. Safarik University, for constant support and advising during designation of this trial.

\section{Availability of data and materials}

Data sharing is not applicable to this article as no datasets were generated or analysed during the current study.

\section{Funding}

This study was supported by the Slovak Research and Development Agency under the contract No. APW-16-0490 and by the Scientific Grant Agency of the Ministry of Education, Science, Research and Sport of the Slovak Republic and the Slovak Academy of Sciences under the contract No. VEGA-1/0825/17.

\section{Authors' contributions}

$A B, P B$ and $A Z$ had the original idea for the project, wrote the study proposal, and obtained funding for the study. PB, PK, IM and JP designed the study and initiated the cooperation with CHCs. AZ wrote the final manuscript, in close cooperation with JPVD, SAR and PK. The manuscript was discussed, edited and revised by all authors. All authors read and approved the final manuscript.

\section{Ethics approval and consent to participate}

The protocol was approved by the Human Research Ethics Committee of Pavol Jozef Safarik University in Kosice (approval no. PJSU-V-0825/17-1). The study protocol is registered at ClinicalTrials.gov (ID:NCT03329053). Prior to a prospective patient's participation in the trial, the written informed consent form will be signed and personally dated by the patient.

\section{Consent for publication}

Not applicable

\section{Competing interests}

The authors declare that they have no competing interests.

\section{Publisher's Note}

Springer Nature remains neutral with regard to jurisdictional claims in published maps and institutional affiliations.

\section{Author details}

${ }^{1}$ Institute of Physical Education and Sport, P. J. Safarik University, Ondavska 21, 04011 Kosice, Slovakia. ${ }^{2}$ Graduate School Kosice Institute for Society and Health, Faculty of Medicine, P. J. Safarik University, Trieda SNP 1, 04011 Kosice, Slovakia. ${ }^{3}$ Department of Health Psychology, Faculty of Medicine, P. J. Safarik University, Trieda SNP 1, 04011 Kosice, Slovakia. ${ }^{4}$ Olomouc University Society and Health Institute, Palacky University Olomouc, Krizkovskeho 8, 771 47 Olomouc, Czech Republic. ${ }^{5}$ First Department of Internal Medicine, Faculty of Medicine, P. J. Safarik University, Trieda SNP 1, 04011 Kosice, Slovakia.

${ }^{6}$ Department of Community and Occupational Medicine, University Medical Center Groningen, University of Groningen, Hanzeplein 1, 9700 Groningen, $\mathrm{RB}$, Netherlands

Received: 7 November 2017 Accepted: 21 March 2018

Published online: 04 April 2018

\section{References}

1. Wilkins E, Wilson L, Wickramasinghe $K$, Bhatnagar $P$, Leal J, LuengoFernandez R, Burns R, Rayner M, Townsend N. European cardiovascular disease statistics 2017. Brussels: European Heart Network; 2017.

2. European Association of Cardiovascular Prevention and Rehabilitation Committee for Science Guidelines, EACPR, Corrà U, Piepoli MF, Carré F, Heuschmann P, Hoffmann U, Verschuren M, Halcox J, Document Reviewers, Giannuzzi P, Saner H, Wood D, Piepoli MF, Corrà U, Benzer W, BjarnasonWehrens B, Dendale P, Gaita D, Mcgee H, Mendes M, Niebauer J, Zwisler $A D$, Schmid JP. Secondary prevention through cardiac rehabilitation: physical activity counselling and exercise training: key components of the position paper from the cardiac rehabilitation section of the European 
Association of Cardiovascular Prevention and Rehabilitation. Eur Heart J. 2010;31(16):1967-74. https://doi.org/10.1093/eurheartj/ehq236.

3. Olsen MH, Angell SY, Asma S, Boutouyrie P, Burger D, Chirinos JA, Damasceno A, Delles C, Gimenez-Roqueplo AP, Hering D, López-Jaramillo P, Martinez F, Perkovic V, Rietzschel ER, Schillaci G, Schutte AE, Scuteri A, Sharman JE, Wachtell K, Wang JG. A call to action and a lifecourse strategy to address the global burden of raised blood pressure on current and future generations: the lancet commission on hypertension. Lancet. 2016; 388(10060):2665-712. https://doi.org/10.1016/50140-6736(16)31134-5.

4. Piepoli MF, Corrà U, Dendale P, Frederix I, Prescott E, Schmid JP, Cupples M, Deaton C, Doherty P, Giannuzzi P, Graham I, Hansen TB, Jennings C, Landmesser U, Marques-Vidal P, Vrints C, Walker D, Bueno H, Fitzsimons D, Pelliccia A. Challenges in secondary prevention after acute myocardial infarction: a call for action. Eur Heart J Acute Cardiovasc Care. 2017;6(4):299310. https://doi.org/10.1177/2048872616689773.

5. Vigorito C, Abreu A, Ambrosetti M, Belardinelli R, Corrà U, Cupples M, Davos CH, Hoefer S, lliou MC, Schmid JP, Voeller H, Doherty P. Frailty and cardiac rehabilitation: a call to action from the EAPC cardiac rehabilitation section. Eur J Prev Cardiol. 2017;24(6):577-90. https://doi.org/10.1177/ 2047487316682579.

6. WHO. Global action plan for the prevention and control of NCDs 20132020. Geneva: WHO; 2013.

7. Inder JD, Carlson DJ, Dieberg G, McFarlane JR, Hess NC, Smart NA. Isometric exercise training for blood pressure management: a systematic review and meta-analysis to optimize benefit. Hypertens Res. 2016;39(2):88-94. https:// doi.org/10.1038/hr.2015.111.

8. Cornelissen VA, Smart NA. Exercise training for blood pressure: a systematic review and meta-analysis. J Am Heart Assoc. 2013;2(1):e004473. https://doi. org/10.1161/JAHA.112.004473.

9. Hulkkonen J, Aatola H, Pälve K, Lehtimäki T, Hutri-Kähönen N, Viikari JS, Raitakari OT, Kähönen M. Determinants of exercise peak arterial blood pressure, circulatory power, and exercise cardiac power in a population based sample of Finnish male and female aged 30 to 47 years: the cardiovascular risk in young Finns study. BMC Cardiovasc Disord. 2014;14:35. https://doi.org/10.1186/1471-2261-14-35.

10. García-Ortiz L, Recio-Rodríguez Jl, Puig-Ribera A, Lema-Bartolomé J, Ibáñez-Jalón E, González-Viejo N, Guenaga-Saenz N, Agudo-Conde C, Patino-Alonso MC, Gomez-Marcos MA, EVIDENT Group. Blood pressure circadian pattern and physical exercise assessment by accelerometer and 7-day physical activity recall scale. Am J Hypertens. 2014;27(5):665-73. https://doi.org/10.1093/ajh/hpt159.

11. Kelley GA, Sharpe Kelley K. Aerobic exercise and resting blood pressure in older adults: a meta-analytic review of randomized controlled trials. J Gerontol A Biol Sci Med Sci. 2001;56(5):M298-303.

12. Mota MR, de Oliveira RJ, Dutra MT, Pardono E, Terra DF, Lima RM, Simões $\mathrm{HG}$, da Silva FM. Acute and chronic effects of resistive exercise on blood pressure in hypertensive elderly women. J Strength Cond Res. 2013;27(12): 3475-80. https://doi.org/10.1519/JSC.0b013e31828f2766.

13. Brito Ade F, de Oliveira CV, Brasileiro-Santos Mdo S, Santos Ada C. Resistance exercise with different volumes: blood pressure response and forearm blood flow in the hypertensive elderly. Clin Interv Aging. 2014;9: 2151-8. https://doi.org/10.2147/CIA.S53441.

14. Dimeo F, Pagonas N, Seibert F, Arndt R, Zidek W, Westhoff TH. Aerobic exercise reduces blood pressure in resistant hypertension. Hypertension. 2012;60(3):653-8. https://doi.org/10.1161/HYPERTENSIONAHA.112.197780.

15. Guimarães GV, Cruz LG, Tavares AC, Dorea EL, Fernandes-Silva MM, Bocchi EA. Effects of short-term heated water-based exercise training on systemic blood pressure in patients with resistant hypertension: a pilot study. Blood Press Monit. 2013;18(6):342-5. https://doi.org/10.1097/MBP.0000000000000000.

16. Ashor AW, Lara J, Siervo M, Celis-Morales C, Oggioni C, Jakovljevic DG, Mathers JC. Exercise modalities and endothelial function: a systematic review and dose-response meta-analysis of randomized controlled trials. Sports Med. 2015;45(2):279-96. https://doi.org/10.1007/s40279-014-0272-9.

17. Farah C, Nascimento A, Bolea G, Meyer G, Gayrard S, Lacampagne A, Cazorla $\mathrm{O}$, Reboul C. Key role of endothelium in the eNOS-dependent cardioprotection with exercise training. J Mol Cell Cardiol. 2017;102:26-30. https://doi.org/10.1016/j.yjmcc.2016.11.008.

18. Guo Y, Ledesma RA, Peng R, Liu Q, Xu D. The beneficial effects of cardiac rehabilitation on the function and levels of endothelial progenitor cells. Heart Lung Circ. 2017;26(1):10-7. https://doi.org/10.1016/j.hlc.2016.06.1210.

19. Walsh JH, Yong G, Cheetham C, Watts GF, O'Driscoll GJ, Taylor RR, Green DJ. Effects of exercise training on conduit and resistance vessel function in treated and untreated hypercholesterolaemic subjects. Eur Heart J. 2003; 24(18):1681-9.

20. Pearson MJ, Smart NA. Effect of exercise training on endothelial function in heart failure patients: a systematic review meta-analysis. Int J Cardiol. 2017; 231:234-43. https://doi.org/10.1016/j.jicard.2016.12.145.

21. DeSouza CA, Shapiro LF, Clevenger CM, Dinenno FA, Monahan KD, Tanaka $\mathrm{H}$, Seals DR. Regular aerobic exercise prevents and restores age-related declines in endothelium-dependent vasodilation in healthy men. Circulation. 2000;102(12):1351-7.

22. de Moraes AC, Fernández-Alvira JM, Carvalho HB, Meirhaeghe A, Dallongeville J, Kafatos A, Marcos A, Molnar D, Manios Y, Ruiz JR, Labayen I, Widhalm K, Breidenassel C, Gonzalez-Gróss M, Moreno LA. Physical activity modifies the associations between genetic variants and blood pressure in European adolescents. J Pediatr. 2014;165(5):1046-9.e1-2. https://doi.org/10. 1016/j.jpeds.2014.07.007.

23. Umpierre D, Ribeiro PA, Schaan BD, Ribeiro JP. Volume of supervised exercise training impacts glycaemic control in patients with type 2 diabetes: a systematic review with meta-regression analysis. Diabetologia. 2013;56(2): 242-51. https://doi.org/10.1007/s00125-012-2774-z.

24. Mann S, Beedie C, Jimenez A. Differential effects of aerobic exercise, resistance training and combined exercise modalities on cholesterol and the lipid profile: review, synthesis and recommendations. Sports Med. 2014; 44(2):211-21. https://doi.org/10.1007/s40279-013-0110-5.

25. Sarzynski MA, Burton J, Rankinen T, Blair SN, Church TS, Després JP, Hagberg JM, Landers-Ramos R, Leon AS, Mikus CR, Rao DC, Seip RL, Skinner JS, Slentz CA, Thompson PD, Wilund KR, Kraus WE, Bouchard C. The effects of exercise on the lipoprotein subclass profile: a meta-analysis of 10 interventions. Atherosclerosis. 2015;243(2):364-72. https://doi.org/10.1016/.jatherosclerosis.2015.10.018.

26. Albert CM, Mittleman MA, Chae CU, Lee IM, Hennekens CH, Manson JE. Triggering of sudden death from cardiac causes by vigorous exertion. $\mathrm{N}$ Engl J Med. 2000;343(19):1355-61.

27. Thompson PD, Franklin BA, Balady GJ, Blair SN, Corrado D, Estes NA 3rd, Fulton JE, Gordon NF, Haskell WL, Link MS, Maron BJ, Mittleman MA, Pelliccia A, Wenger NK, Willich SN, Costa F, American Heart Association Council on Nutrition, Physical Activity, and Metabolism, American Heart Association Council on Clinical Cardiology, American College of Sports Medicine. Exercise and acute cardiovascular events placing the risks into perspective: a scientific statement from the American Heart Association Council on nutrition, physical activity, and metabolism and the council on clinical cardiology. Circulation. 2007;115(17):2358-68.

28. Fagard RH, Björnstad HH, Børjesson M, Carré F, Deligiannis A, Vanhees L, European Society of Cardiology. ESC study Group of Sports Cardiology recommendations for participation in leisure-time physical activities and competitive sports for patients with hypertension. Eur I Cardiovasc Prev Rehabil. 2005;12(4):326-31.

29. ESC Study Group of Sports Cardiology, Börjesson M, Assanelli D, Carré F, Dugmore D, Panhuyzen-Goedkoop NM, Seiler C, Senden J, Solberg EE. ESC study Group of Sports Cardiology: recommendations for participation in leisure-time physical activity and competitive sports for patients with ischaemic heart disease. Eur J Cardiovasc Prev Rehabil. 2006;13(2):137-49.

30. Hirth A, Reybrouck T, Bjarnason-Wehrens B, Lawrenz W, Hoffmann A. Recommendations for participation in competitive and leisure sports in patients with congenital heart disease: a consensus document. Eur J Cardiovasc Prev Rehabil. 2006;13(3):293-9.

31. Pelliccia A, Corrado D, Bjørnstad HH, Panhuyzen-Goedkoop N, Urhausen A, Carre F, Anastasakis A, Vanhees L, Arbustini E, Priori S. Recommendations for participation in competitive sport and leisure-time physical activity in individuals with cardiomyopathies, myocarditis and pericarditis. Eur J Cardiovasc Prev Rehabil. 2006;13(6):876-85.

32. Heidbüchel H, Panhuyzen-Goedkoop N, Corrado D, Hoffmann E, Biffi A, Delise P, Blomstrom-Lundqvist C, Vanhees L, Ivarhoff P, Dorwarth U, Pelliccia A, Study Group on Sports Cardiology of the European Association for Cardiovascular Prevention and Rehabilitation. Recommendations for participation in leisure-time physical activity and competitive sports in patients with arrhythmias and potentially arrhythmogenic conditions part l: supraventricular arrhythmias and pacemakers. Eur I Cardiovasc Prev Rehabil. 2006;13(4):475-84

33. Heidbüchel H, Corrado D, Biffi A, Hoffmann E, Panhuyzen-Goedkoop N, Hoogsteen J, Delise P, Hoff PI, Pelliccia A, Study Group on Sports Cardiology of the European Association for Cardiovascular Prevention and Rehabilitation. Recommendations for participation in leisure-time physical activity and 
competitive sports of patients with arrhythmias and potentially arrhythmogenic conditions. Part II: ventricular arrhythmias, channelopathies and implantable defibrillators. Eur J Cardiovasc Prev Rehabil. 2006;13(5):676-86.

34. Vanhees L, De Sutter J, GeladaS N, Doyle F, Prescott E, Cornelissen V, Kouidi E, Dugmore D, Vanuzzo D, Börjesson M, Doherty P, EACPR. Importance of characteristics and modalities of physical activity and exercise in defining the benefits to cardiovascular health within the general population: recommendations from the EACPR (part I). Eur J Prev Cardiol. 2012;19(4): 670-86. https://doi.org/10.1177/2047487312437059.

35. Vanhees L, Geladas N, Hansen D, Kouidi E, Niebauer J, Reiner Z, Cornelissen V, Adamopoulos S, Prescott E, Börjesson M, Bjarnason-Wehrens B, Björnstad HH, Cohen-Solal A, Conraads V, Corrado D, De Sutter J, Doherty P, Doyle F, Dugmore D, Ellingsen $\varnothing$, Fagard R, Giada F, Gielen S, Hager A, Halle M Heidbüchel H, Jegier A, Mazic S, McGee H, Mellwig KP, Mendes M, Mezzan A, Pattyn N, Pelliccia A, Piepoli M, Rauch B, Schmidt-Trucksäss A, Takken T, van Buuren F, Vanuzzo D. Importance of characteristics and modalities of physical activity and exercise in the management of cardiovascular health in individuals with cardiovascular risk factors: recommendations from the EACPR. Part II. Eur J Prev Cardiol. 2012;19(5):1005-33.

36. Vanhees $L$, Rauch $B$, Piepoli M, van Buuren F, Takken T, Börjesson M, Bjarnason-Wehrens B, Doherty P, Dugmore D, Halle M, Writing Group, EACPR. Importance of characteristics and modalities of physical activity and exercise in the management of cardiovascular health in individuals with cardiovascular disease (part III). Eur J Prev Cardiol. 2012;19(6):1333-56.

37. Piepoli MF, Hoes AW, Agewall S, Albus C, Brotons C, Catapano AL, Cooney MT, Corrà U, Cosyns B, Deaton C, Graham I, Hall MS, Hobbs FD, Løchen ML, Löllgen H, Marques-Vidal P, Perk J, Prescott E, Redon J, Richter DJ, Sattar N, Smulders Y, Tiberi M, van der Worp HB, van Dis I, Verschuren WM, Authors/ Task Force Members. 2016 European guidelines on cardiovascular disease prevention in clinical practice: the sixth joint task force of the European Society of Cardiology and Other Societies on cardiovascular disease prevention in clinical practice (constituted by representatives of 10 societies and by invited experts) developed with the special contribution of the European Association for Cardiovascular Prevention \& rehabilitation (EACPR). Eur Heart J. 2016;37(29):2315-81. https://doi.org/10.1093/eurheartj/ehw106.

38. Liakos Cl, Grassos CA, Babalis DK, European Society of Hypertension European Society of Cardiology. 2013 ESH/ESC guidelines for the management of arterial hypertension: what has changed in daily clinical practice? High Blood Press Cardiovasc Prev. 2015;22(1):43-53. https://doi. org/10.1007/s40292-014-0071-2

39. Kotseva K, Wood D, De Bacquer D, De Backer G, Rydén L, Jennings C, Gyberg V, Amouyel P, Bruthans J, Castro Conde A, Cífková R, Deckers JW, De Sutter J, Dilic M, Dolzhenko M, Erglis A, Fras Z, Gaita D, Gotcheva N, Goudevenos J, Heuschmann P, Laucevicius A, Lehto S, Lovic D, Miličić D, Moore D, Nicolaides E, Oganov R, Pajak A, Pogosova N, Reiner Z, Stagmo M, Störk S, Tokgözoğlu L, Vulic D, EUROASPIRE Investigators. EUROASPIRE IV: a European Society of Cardiology survey on the lifestyle, risk factor and therapeutic management of coronary patients from 24 European countries. Eur J Prev Cardiol. 2016;23(6): 636-48. https://doi.org/10.1177/2047487315569401.

40. Berben L, Dobbels F, Engberg S, Hill MN, De Geest S. An ecological perspective on medication adherence. West J Nurs Res. 2012;34(5):635-53. https://doi.org/10.1177/0193945911434518.

41. Cramm JM, Nieboer AP. The importance of productive patient-professional interaction for the well-being of chronically ill patients. Qual Life Res. 2015; 24(4):897-903. https://doi.org/10.1007/s11136-014-0813-6.

42. Zolnierek KB, Dimatteo MR. Physician communication and patient adherence to treatment: a meta-analysis. Med Care. 2009;47(8):826-34. https://doi.org/10.1097/MLR.0b013e31819a5acc.

43. McKenna VB, Sixsmith J, Barry MM. The relevance of context in understanding health literacy skills: findings from a qualitative study. Health Expect. 2017;20(5):1049-60. https://doi.org/10.1111/hex.12547.

44. van Schaik TM, Jørstad HT, Twickler TB, Peters RJG, Tijssen JPG, Essink-Bot ML, Fransen MP. Cardiovascular disease risk and secondary prevention of cardiovascular disease among patients with low health literacy. Neth Heart J. 2017;25(7-8):446-54. https://doi.org/10.1007/s12471-017-0963-6.

45. Institute of Medicine (US) Committee on Health Literacy, Nielsen-Bohlman L, Panzer AM, Kindig DA. Health literacy: a prescription to end confusion. Washington: National Academies Press (US); 2004.

46. Berkman ND, Sheridan SL, Donahue KE, Halpern DJ, Crotty K. Low health literacy and health outcomes: an updated systematic review. Ann Intern Med. 2011;155(2):97-107. https://doi.org/10.7326/0003-4819-155-2-201107190-00005.
47. Geboers B, de Winter AF, Luten KA, Jansen CJ, Reijneveld SA. The association of health literacy with physical activity and nutritional behavior in older adults, and its social cognitive mediators. J Health Commun. 2014; 19(Suppl 2):61-76. https://doi.org/10.1080/10810730.2014.934933.

48. Koh HK, Brach C, Harris LM, Parchman ML. A proposed 'health literate care model' would constitute a systems approach to improving patients' engagement in care. Health Aff (Millwood). 2013;32(2):357-67. https://doi. org/10.1377/hlthaff.2012.1205.

49. Zullig LL, McCant F, Melnyk SD, Danus S, Bosworth HB. A health literacy pilot intervention to improve medication adherence using Meducation ${ }^{\circledast}$ technology. Patient Educ Couns. 2014;95(2):288-91. https://doi.org/10.1016/j. pec.2014.02.004

50. Martin SS, Feldman DI, Blumenthal RS, Jones SR, Post WS, McKibben RA, Michos ED, Ndumele CE, Ratchford EV, Coresh J, Blaha MJ. mActive: a randomized clinical trial of an automated mHealth intervention for physical activity promotion. J Am Heart Assoc. 2015;4(11) https://doi.org/10.1161/ JAHA.115.002239.

51. Franklin NC, Lavie CJ, Arena RA. Personal health technology: a new era in cardiovascular disease prevention. Postgrad Med. 2015;127(2):150-8. https:// doi.org/10.1080/00325481.2015.1015396.

52. Hansen D, Dendale $P$, Coninx K Vanhees L, Piepoli MF, Niebauer J, Cornelissen V, Pedretti R, Geurts E, Ruiz GR, Corrà U, Schmid JP, Greco E, Davos CH, Edelmann F, Abreu A, Rauch B, Ambrosetti M, Braga SS, Barna O, Beckers P, Bussotti M, Fagard R, Faggiano P, Garcia-Porrero E, Kouidi E, Lamotte M, Neunhäuserer D, Reibis R, Spruit MA, Stettler C, Takken T, Tonoli C, Vigorito C, Völler H, Doherty P. The European Association of Preventive Cardiology Exercise Prescription in everyday practice and rehabilitative training (EXPERT) tool: a digital training and decision support system for optimized exercise prescription in cardiovascular disease. Concept, definitions and construction methodology. Eur J Prev Cardiol. 2017;24(10): 1017-31. https://doi.org/10.1177/2047487317702042.

53. Chan AW, Tetzlaff JM, Altman DG, Laupacis A, Gøtzsche PC, Krleža-Jerić K, Hróbjartsson A, Mann H, Dickersin K, Berlin JA, Doré CJ, Parulekar WR, Summerskill WS, Groves T, Schulz KF, Sox HC, Rockhold FW, Rennie D, Moher D. SPIRIT 2013 statement: defining standard protocol items for clinical trials. Ann Intern Med. 2013;158(3):200-7. https://doi.org/10.7326/ 0003-4819-158-3-201302050-00583.

54. Authors/Task Force Members, Piepoli MF, Hoes AW, Agewall S, Albus C, Brotons C, Catapano AL, Cooney MT, Corrà U, Cosyns B, Deaton C, Graham I, Hall MS, Hobbs FD, Løchen ML, Löllgen H, Marques-Vidal P, Perk J, Prescott E, Redon J, Richter DJ, Sattar N, Smulders Y, Tiberi M, van der Worp HB, van Dis I, Verschuren WM, Additional Contributor: Simone Binno (Italy), Document Reviewers, De Backer G, Roffi M, Aboyans V, Bachl N, Bueno H, Carerj S, Cho L, Cox J, De Sutter J, Egidi G, Fisher M, Fitzsimons D, Franco $\mathrm{OH}$, Guenoun M, Jennings $\mathrm{C}$, Jug B, Kirchhof P, Kotseva K, Lip GY, Mach F, Mancia G, Bermudo FM, Mezzani A, Niessner A, Ponikowski P, Rauch B, Rydén L, Stauder A, Turc G, Wiklund O, Windecker S, Zamorano JL. 2016 European guidelines on cardiovascular disease prevention in clinical practice: the sixth joint task force of the European Society of Cardiology and Other Societies on cardiovascular disease prevention in clinical practice (constituted by representatives of 10 societies and by invited experts): developed with the special contribution of the European Association for Cardiovascular Prevention \& rehabilitation (EACPR). Eur J Prev Cardiol. 2016; 23(11):NP1-NP96. https://doi.org/10.1177/2047487316653709.

55. Craig $C L$, Marshall AL, Sjöström M, Bauman AE, Booth ML, Ainsworth BE, Pratt M, Ekelund U, Yngve A, Sallis JF, Oja P. International physical activity questionnaire: 12-country reliability and validity. Med Sci Sports Exerc. 2003; 35(8):1381-95.

56. Arredondo EM, Mendelson T, Holub C, Espinoza N, Marshall S. Cultural adaptation of physical activity self-report instruments. J Phys Act Health. 2012;9(Suppl 1):S37-43.

57. Sperber AD, Devellis RF, Boehlecke B. Cross-cultural translation: methodology and validation. J Cross-Cult Psychol. 1994;25(4):501-24.

58. Osborne RH, Batterham RW, Elsworth GR, Hawkins M, Buchbinder R. The grounded psychometric development and initial validation of the health literacy questionnaire (HLQ). BMC Public Health. 2013;13:658. https://doi.org/ 10.1186/1471-2458-13-658.

59. Kolarcik P, Cepova E, Madarasova Geckova A, Elsworth GR, Batterham RW, Osborne RH. Structural properties and psychometric improvements of the health literacy questionnaire in a Slovak population. Int J Public Health. 2017;62(5):591-604. https://doi.org/10.1007/s00038-017-0945-x. 
60. Cicero AF, D'Addato S, Santi F, Ferroni A, Borghi C. Brisighella heart study. Leisure-time physical activity and cardiovascular disease mortality: the Brisighella heart study. J Cardiovasc Med (Hagerstown). 2012;13(9):559-64.

61. Savela S, Koistinen P, Tilvis RS, Strandberg AY, Pitkälä KH, Salomaa W,

Miettinen TA, Strandberg TE. Leisure-time physical activity, cardiovascular risk factors and mortality during a 34-year follow-up in men. Eur J

Epidemiol. 2010;25(9):619-25. https://doi.org/10.1007/s10654-010-9483-z.

Submit your next manuscript to BioMed Central and we will help you at every step:

- We accept pre-submission inquiries

- Our selector tool helps you to find the most relevant journal

- We provide round the clock customer support

- Convenient online submission

- Thorough peer review

- Inclusion in PubMed and all major indexing services

- Maximum visibility for your research

Submit your manuscript at www.biomedcentral.com/submit 